\title{
Apresentação Ensino Médio e Juventudes
}

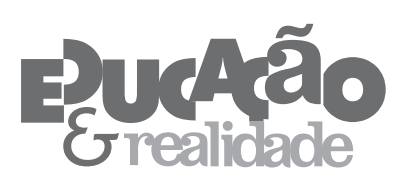

\author{
Paulo Carrano' \\ 'Universidade Federal Fluminense (UFF), Niterói/RJ - Brasil
}

É com alegria que apresentamos o número temático Ensino Médio e Juventudes. Neste momento é possível dizer do êxito da convocatória de artigos para este número especial da Revista Educação \& Realidade. Foram 110 artigos submetidos à análise, número que expressa tanto o interesse pela temática quanto a ampliação do próprio campo de estudos, pesquisas e reflexão sobre as relações entre os jovens e a escola de ensino médio. Escola esta que deveria ser a casa comum da expressiva maioria dos jovens brasileiros não fossem as históricas e persistentes desigualdades de acesso e conclusão deste nível de ensino que sabemos existir, em especial, para os jovens das classes populares. Na chamada para este número dissemos:

A expansão das matrículas de ensino médio no Brasil é relativamente recente. A escola de ensino médio, originalmente destinada às elites intelectuais, recebeu, especialmente nas redes públicas, um novo público popular e plural que justifica a utilização da categoria 'juventudes'. As escolas vivem o desafio cotidiano de produzir relações educacionais significativas no âmbito da socialização de conhecimentos, da abertura para experiências, culturas e saberes de seus jovens estudantes e criação de relacionamentos humanizados e democráticos em seus espaço-tempos. O ensino médio é interpelado pela sociedade para que esta etapa da educação básica seja de qualidade e que 'produza resultados'.

Educação \& Realidade, Porto Alegre, v. 41, n. 1, p. 7-13, jan./mar. 2016. http://dx.doi.org/10.1590/2175-623661287 
Apresentação da Seção Temática - Ensino Médio e Juventudes

Os artigos deste número não esgotam o conjunto das questões e problemas de investigação possíveis de articular e que, em grande medida, expressamos no trecho citado da convocatória para o dossiê. Em verdade, nenhuma publicação poderia ter esta pretensão. De toda forma, o conjunto de artigos comentados abaixo, pela qualidade dos mesmos e abrangência de problemas de investigação enfrentados, são desafiadores. Vamos a eles.

A partir de sua própria trajetória de investigadora experiente dos diferentes âmbitos de constituição do juvenil no Uruguai, Verónica Filardo apresenta e discute, no artigo Integralidad en el Análisis de Trayectorias Educativas, o que chamou de "ideias força" que necessitam ser contempladas para o estabelecimento de análises consistentes sobre as trajetórias escolares de estudantes. Para isso, apresenta e problematiza dados de pesquisa nacional de opinião do Uruguai e estabelece análises tipológicas que nos permitem compreender tanto a integração sistêmica dos níveis educativos em seus diferentes ciclos, notadamente naquilo que se refere às determinações que os resultados em dado ciclo de ensino exercem sobre o subsequente, quanto à influência recíproca entre escola e outros espaços vitais no curso da escolarização, tais como trabalho, vida conjugal e existência de filhos.

Ana Paula Corti, no texto Ensino Médio em São Paulo: a expansão das matrículas nos anos 1990, focaliza a expansão do Ensino Médio público no estado de São Paulo, entre 1991 e 2013, a partir do tratamento de dados de matrículas em quatro diferentes redes de ensino (estadual, particular, municipal e federal) e também entre Região Metropolitana e Interior paulista, sendo que este último revela informações sobre as escolas rurais de ensino médio que sabemos ainda ser pouco problematizadas nos estudos sobre escola e juventude. $\mathrm{O}$ artigo contribui para que possamos pensar e compreender características e consequências de uma relação problemática entre demanda, oferta e realização de expectativas por direitos à escolarização pública de qualidade para as classes populares no Brasil. Uma das conclusões do artigo é reveladora do quadro político-administrativo da gestão da rede estadual paulista que se expressa na simultânea situação de aumento da racionalização e controle da oferta de vagas pelo estado, superlotação de salas de aula e diminuição na autonomia das unidades escolares, que, como nos diz a autora, "perderam a prerrogativa de decidir o método pelo qual a população teria acesso às suas vagas”. Na mesma direção, familiares e seus filhos também teriam perdido a possibilidade de escolha da escola onde estudar. Pode-se dizer, então, que este é um trabalho de base para a compreensão das razões históricas e estruturais da rede pública de São Paulo que culminaram, com uma boa dose de autoritarismo de estado, na recente e, até então, não equacionada crise de reorganização e fechamento de escolas em São Paulo e consequente ocupação cidadã das escolas por estudantes daquele estado ${ }^{1}$. Nesse sentido, o artigo aborda dimensão estratégica para o campo de estudos da juventude que é a escola de ensino médio pelo viés de sua expansão. 
O artigo de Celecina Veras Sales e Maria Aurilene de Deus Moreira Vasconcelos, Ensino Médio Integrado e Juventudes: desafios e projetos de futuro, se realiza em outra escala. No âmbito de um estudo de caso qualitativo as autoras interpretam narrativas de jovens estudantes sobre seus projetos de futuro em escola de Ensino Médio Integrado na cidade de Fortaleza, Ceará. As relações entre projetos educativos, não apenas os escolares, e os jovens são em grande medida colonizadas pela representação do futuro e do vir a ser adulto. Nesse diapasão, não é incomum que o ensino profissionalizante apareça como pedra de toque das orientações educativas, em especial quando se trata de projetar a "boa educação" de jovens pobres. O artigo adquire relevância notadamente por cotejar expectativas institucionais da escola de ensino médio integrado em questão e as projeções dos jovens estudantes em seus desejos de ingressar no ensino superior, entrar no mercado de trabalho e as múltiplas possibilidades que a vida de um bairro popular urbano encerra.

Myrna Cecília Martins dos Santos Amorim, Eloiza Silva Gomes Oliveira, Joel André Ferreira Santos e João Roberto de Toledo Quadros trazem para este dossiê, através do artigo Aprendizagem e Jogos: diálogo com alunos do ensino médio-técnico, uma análise sobre experiência de ensino-aprendizagem por meio de jogos digitais com alunos do ensino médio-técnico de informática. O artigo utiliza conceitos que consideramos simplificadores, tal como "nativos digitais" e "geração Y", sendo estes influenciados pelo campo da propaganda que, em última instância, reduz significativamente o alcance da noção socioantropológica do conceito de geração ${ }^{2}$. Todavia, é artigo instigante, em especial, por colocar em discussão um dos grandes desafios da escola contemporânea que é o de produzir processos significativos de aprendizagens e em sintonia com as subjetividades juvenis contemporâneas. Estas fortemente marcadas pelas mídias digitais e as linguagens de programação.

Denise Helena Pereira Laranjeira, Mirela Figueiredo Santos Iriart e Milena Santos Rodrigues contribuem para este número com um ensaio que "discute as transições juvenis em tempos incertos": Problematizando as Transições Juvenis na Saída do Ensino Médio. Este pode ser entendido como um guia de leitura que recobre, com a utilização de autores contemporâneos de referência, amplo e significativo campo constitutivo dos múltiplos interesses de investigação sobre os jovens, a juventude e o ensino médio. Nessa direção são apresentados conceitos e questões relacionados com as chamadas transições incertas para a vida adulta, a perda de linearidade das etapas de vida, a crise dos programas institucionais das agências clássicas de socialização, o lugar das políticas públicas, o urbano e o rural e o desafio da escolarização com qualidade. As sociabilidades não escolares e as relações significativas que os jovens estabelecem em seus grupos de referência são trazidas para nos lembrar da necessidade de se escutar os jovens em seus territórios comunicativos e, assim, compreender os sinais que estes transmitem às instituições sobre o controle do mundo adulto.

Educação \& Realidade, Porto Alegre, v. 41, n. 1, p. 7-13, jan./mar. 2016. 
Ana Maria Klein e Valeria Amorim Arantes realizaram um estudo na cidade de São Paulo com 305 estudantes do Ensino Médio e produziram, com base nele, o artigo Projetos de Vida de Jovens Estudantes do Ensino Médio e a Escola. A abordagem foi qualitativa (análise de conteúdo e formulação de categorias) e também tratou da percepção de estudantes do Ensino Médio sobre seus projetos de vida. A pesquisa reconheceu nas percepções reveladas o lugar positivo que as experiências escolares, especialmente as realizadas em sala de aula, ocupam nessas projeções.

O sociólogo peruano, radicado na França, Danilo Martuccelli é o colaborador internacional deste dossiê que nos instiga, com o texto Condición Adolescente y Ciudadanía Escolar, a pensar sobre as relações entre a experiência escolar adolescente e os sentidos profundos da cidadania. Martuccelli nos provoca a refletir sobre três grandes eixos do tema da cidadania, a saber: a) a cidadania desde os direitos e as formas sociais efetivas de inserção que os adolescentes possuem na sociedade; b) a forma como o tema da cidadania é abordado considerando os desafios para que os adolescentes sejam atores e suscitem transformações na sociedade; e c) considerações sobre a possibilidade de se exercitar a formação da cidadania adolescente no interior da própria escola. Ao ler pela primeira vez o seu ensaio ocorreu-me uma frase do cineasta Roberto Rosselini que diz assim: "não lhes aparece estranho educar para a democracia em condições de aprisionamento?" E do meu ponto de vista esta frase do cineasta italiano é uma síntese - não autorizada pelo autor, deve-se dizer - das reflexões e desafios que Martuccelli lança para a escola e a sociedade brasileira.

O ensaio de Carmem Zeli Vargas Gil e Fernando Seffner, Dois Monólogos Não Fazem um Diálogo: jovens e ensino médio, segue na trilha da busca de uma escola de ensino médio produtora de relações cidadãs. Nessa perspectiva, problematizam, através de autores de referências e uso de dados secundários sobre a escolarização, o desafio da escola e a agência de seus docentes e gestores. O artigo lança desafio para que a escola se constitua em arena de diálogo em relação de escuta e respeito pelos saberes produzidos pelos jovens fora da escola. A consideração da instituição pelas culturas juvenis é apresentada pelos autores como a chave para a construção de uma escola acolhedora e que saiba escolarizar em quadro de profundas desigualdades.

Beatriz Prado Pereira e Roseli Esquerdo Lopes analisaram dados de pesquisa que combinou método estatístico e conversa coletiva buscando sondar os sentidos da escola para jovens no último ano do Ensino Médio regular na cidade de São Carlos, SP. Da análise de dados emerge uma das características dramáticas da escolarização no ensino médio que vem a ser a sua dependência frente às expectativas dos estudantes frente ao futuro de continuidade nos estudos e inserção profissional. $\mathrm{O}$ artigo, Por que ir à Escola? Os sentidos atribuídos pelos jovens do ensino médio, fornece pistas para se pensar a escolarização significativa 
no tempo presente. Na síntese elaborada pelas autoras, os jovens compõem sentidos positivos e se motivam em relação à escola, não obstante, apontam deficiências nela presentes sem, com isso, desvalorizá-la".

Alexandre Barbosa Pereira traz para este dossiê uma experiência etnográfica em escolas de ensino médio da periferia da cidade de São Paulo. E, neste sentido, "esteve lá", "de perto e de dentro", tal como se diz no bojo das pesquisas ancoradas na observação e na interpretação antropológica. O artigo, Outros Ritmos em Escolas da Periferia de São Paulo, se ancora também, além das experiências juvenis observadas e narradas, em conceitos que contribuem para o estabelecimento de sínteses criativas evitando que o observado se perca na soma de seus fragmentos. $\mathrm{O}$ artigo permite perceber, então, entrelaçamentos entre a multiplicidade de experiências, tempos-espaços, simbolismos, corpos atuantes e diferenciações rítmicas de jovens e instituições.

Vanessa Gomes de Castro e Fernando Tavares Júnior enfrentam a questão das desigualdades educacionais com base em dados nacionais do SAEB/INEP. O artigo, Jovens em Contextos Sociais Desfavoráveis e Sucesso Escolar no Ensino Médio, analisa o perfil de jovens em contextos sociais desfavoráveis que chegaram com sucesso ao terceiro ano do ensino médio. Há no artigo conexão estratégica para os estudos da juventude que é o papel do background familiar para o sucesso escolar, sendo este definido como a chegada ao terceiro ano do ensino médio em idade apropriada. As conclusões são cautelosas, ancoradas em evicências e abrem perspectivas para novos estudos.

O artigo de Karoliny Correia, Projetos de Letramento no Ensino Médio: novas perspectivas e desafios, também aborda questões significativas para a relação ensino-aprendizagem na escola de ensino médio. $\mathrm{O}$ artigo discute resultados de pesquisa-ação junto à acadêmicos do PIBID do Curso de Letras Português (UFSC) atuantes em turma do terceiro ano do Ensino Médio de escola pública. A análise segue as pistas dos demais artigos que enfatizam a importância da constituição de aprendizagens significativas no cotidiano escolar. Nessa perspectiva, chama a atenção para a necessidade de que o trabalho com os projetos de letramento na escola atente para necessidades, interesses e contextos de inserção dos alunos.

O artigo de Cirlene Cristina de Sousa e Geraldo Magela Pereira Leão, Ser Jovem e Ser Aluno: entre a escola e o Facebook, discute resultados de pesquisa qualitativa que trata da relação entre juventude e midiatização da cultura contemporânea com jovens estudantes em três turmas do ensino médio, em Minas Gerais. Os dados utilizados para as análises são provenientes de instrumentos e estratégicas metodológicas combinadas (questionário estruturado, entrevistas, grupos de discussão, análise de documentos e de interações on line e off line). Os resultados indicaram que jovens pesquisados vivenciavam conexões midiáticas amplas e heterogêneas, permeando seus tempos e espaços, 
vínculos afetivos e comunicacionais e experiências escolares de diferentes formas segundo a situação juvenil em observação. $\mathrm{O}$ artigo chama a atenção para os nexos entre a sala de aula e o espaço-tempo das redes sociotécnicas da internet, onde se joga um jogo decisivo de formação do humano.

A escola de ensino médio pode ser pensada como um dos muitos e significativos nós das múltiplas redes de formação e constituição das subjetividades juvenis. Poderia ser mesmo, para a totalidade dos jovens brasileiros e latino-americanos, um centro cultural, científico e tecnológico de formação superior e não apenas escada para a universidade ou ponte de treinamento para o mercado de trabalho. Cada vez mais jovens declaram que querem passar rápido pela escola, em especial, quando diante de escolas que são vazias de significado; que, por não produzirem o sabor de ser e estar, sacrificam o saber. Estamos diante de jovens que encontram nas tecnologias digitais suportes para os seus relacionamentos e modos de viver o tempo da juventude. E a escola ainda, na maioria dos casos, resiste ao diálogo com as novas temporalidades e espacialidades do mundo digital.

A leitura deste número temático de Educação \& Realidade pode nos ajudar a pensar numa escola de ensino médio que simultaneamente seja para todos, como realizadora dos princípios de igualdade, mas que faça sentido para cada um e cada uma de seus jovens estudantes.

Os artigos comentados provocam a pensar em escalas de investigação, historicidades, estruturas de oportunidades educacionais, multiplicidade de tempos e espaços de interação e constituição das subjetividades juvenis. Os jovens e as jovens estão na escola, o processo formativo se complexifica com a interferência da mesma, mas, em última instância, o educativo escolar precisa ser pensado em diálogo com muitas outras instâncias socializadores, campos culturais e estruturas socioeconômicas delimitadoras, produtoras de heranças e constitutivas do "ser jovem" no tempo presente. Este nos parece o sentido maior do desafio à leitura que este dossiê nos faz.

\section{Notas}

1 A ANPEd produziu artigo de análise sobre a cobertura dada pela mídia, tradicional e alternativa, às ocupações das escolas em São Paulo. Ver ANPED (2015).

2 Sobre o conceito de geração, ver Cicchelli (2001), Mannheim (1993) e Weller (2010). 


\section{Referências}

ANPED. Portal da ANPED. De Olho na Mídia: Ocupações das escolas em SP. ANPEd analisa estratégias na cobertura da imprensa tradicional e alternativa durante os protestos contra a reorganização do ensino estadual paulista. Reportagem de Tatiana Carvalho. Rio de Janeiro, 22 dez. 2015. Disponível em: <http://www.anped.org.br/news/de-olho-na-midia-ocupacoes-das-escolas-em-sp>. Acesso em: 30 dez. 2015.

CICCHELLI, Vincenzo. Repensar os laços entre pais e jovens adultos fora da aporia conflito/entendimento. Interseções: Revista de Estudos Interdisciplinares, Rio de Janeiro, v. 3, n. 2, p. 247-265, 2001. Disponível em: <https://www. dropbox.com/s/4856j6zz0jzexgm/vincenzo.rtf?dl=0 >. Acesso em: 21 nov. 2015

MANNHEIM, Karl. El problema de las generaciones. Tradução: Ignacio Sánchez de la Yncera. Revista Española de Investigaciones Sociológicas (REIS), Madrid, n. 62, p. 193-242, 1993. Disponível em: <http://www.reis.cis.es/REIS/PDF/ REIS_062_12.pdf>. Acesso em: 21 nov. 2015.

WELLER, Wivian. A atualidade do conceito de gerações de Karl Mannheim. Revista Sociedade e Estado, Brasília, v. 25, n. 2, p. 205-224, maio/ago. 2010. Disponível em: < http://www.scielo.br/pdf/se/v25n2/04.pdf>. Acesso em: 21 nov. 2015.

Paulo Carrano é professor do Programa de Pós-Graduação da Universidade Federal Fluminense. Pesquisador do CNPq - Nível 2. Bolsista Cientista do Nosso Estado - FAPERJ.

E-mail:pc.carrano@gmail.com 